\title{
Editorial for EAIT issue 6, 2019
}

\section{Arthur Tatnall $^{1}$}

Published online: 15 October 2019

(C) Springer Science+Business Media, LLC, part of Springer Nature 2019

Education and Information Technologies (EAIT) is the official journal of the IFIP Technical Committee on Education (TC3) and covers the complex relationships between information and communication technologies and education, from the micro of specific applications or instances of use in classrooms to macro concerns of national policies and major projects; from classes of five year olds to adults in tertiary institutions; from teachers and administrators, to researchers and designers; from institutions to open, distance and lifelong learning. The journal's breadth of coverage allows EAIT to examine fundamental issues at all levels, discuss specific instances and cases, draw inference and probe theory. This journal is embedded in the research and practice of professionals.

This issue relates to research by academics from: India, South Africa, Iran, USA, Saudi Arabia, Turkey, Norway, Malaysia, Pakistan, Fiji, Morocco, Estonia, Japan, France, Spain, Greece, United Arab Emirates, Ghana, Nicaragua, Northern Ireland, Ireland, UK and Oman.

The first article is by Saurabh Pal (Bengal Institute of Technology, Kolkata, India), Pijush Kanti Dutta Pramanik (National Institute of Technology, Durgapur, India), Tripti Majumdar (Bengal Institute of Technology, Kolkata, India) and Prasenjit Choudhury (National Institute of Technology, Durgapur, India) and is titled: $\boldsymbol{A}$ semi-automatic metadata extraction model and method for video-based e-learning contents. The authors note that although video-based learning offers a learner a self-paced and flexible way of learning, lack of information about the videos' relevancy and difficulty makes it difficult for the learner to search and select the video required. Educational video recommendation systems also suffer from a similar problem. Their paper proposes a comprehensive approach to extraction of educational metadata from a learning video.

ICT-related training and support Programmes for information professionals from Rexwhite Tega Enakrire (University of South Africa, Pretoria, South Africa) seeks to investigate ICT-related training and support programmes for information professionals. A questionnaire was used to collect data from respondents in selected university

Arthur Tatnall

Arthur.Tatnall@vu.edu.au

1 Victoria University, Melbourne, Australia 
libraries in Africa. Findings revealed that ICT-related training and support programmes offered to information professionals helped to improve current practices of library operations and service delivery to users.

Next comes: Investigating medical students' readiness for technology-mediated autonomous learning situations in ESP programs by Iman Alizadeh (Guilan University of Medical Sciences, Rasht, Iran) and Farideh Ebrahimi (Babol Noshirvani University of Technology, Babol, Iran). They maintain that use of technology and learner autonomy are two key issues in English for Specific Purposes (ESP) programs, and their study aimed to investigate Iranian medical students' readiness to do ESP tasks based on five different situations and to discover their reasons for choosing each of the situations. The study concluded that the majority of students have a low level of readiness for technology-mediated autonomous learning situations.

Jason A. Engerman (East Stroudsburg University, Rosenkrans East, USA), Alison A. Carr-Chellman (University of Idaho, Moscow, USA) and Monique MacAllan (Pennsylvania State University, USA) then offer: Understanding learning in video games: A phenomenological approach to unpacking boy cultures in virtual worlds. Their paper describes the findings of a phenomenological research study to uncover possible skills that boys learn through peer supported activities using Commercial OffThe-Shelf (COTS) video games. By drawing on a cultural-historical activity theory (CHAT) conceptual framework and prioritizing student voice, the study found that boys engaged in a variety of non-cognitive skills through their COTS video gameplay.

Adaptive hypermedia instructional system (AHIS): A model describes a model for instructional system design, and develops a system based on Merrill's Component Display Theory incorporating appropriate selection of Media, Ergonomics and Navigation Structures to produce learner engaging and effective learning outcome. The authors are: Mohd Javed Khan and Khurram Mustafa (Jamia Millia Islamia, New Delhi, India). A significant component of the proposed model is the integration of principles of Ergonomics having Graphic Aesthetic as one of the constituent.

The article that follows: Auditing the TPACK confidence of pre-service teachers: The case of Saudi Arabia was contributed by Ahlam Mohammed Al-Abdullatif (King Faisal University, Al Ahssa, Saudi Arabia). It describes a study that investigated the technological knowledge and technological pedagogical and content knowledge (TPACK) confidence of Saudi pre-service teacher students who were in their final year of the teacher education program. The results indicated a high percentage of participants had a very low level of perceived competences while using digital technologies for teaching and learning. Female pre-service teacher participants exhibited a more significant confidence and readiness to engage in information and communication technology practices to transform learning outcomes of students.

Sacide Güzin Mazman Akar (Usak University, Turkey) next presents: Does it matter being innovative: Teachers' technology acceptance. Teachers' technology adoption has been the focus of many researches and various factors affecting adoption process have been examined. This study aimed to investigate the effect of teachers' personal innovativeness on their technology acceptance. The results revealed that for most teachers their innovativeness level was low. Perceived usefulness and perceived ease of use of highly innovative teachers were found to be significantly higher than their low level counterparts. 
Exploring the role of blended learning for teaching and learning effectiveness in institutions of higher learning: An empirical investigation comes from a large group of researchers: Bokolo Anthony Jr. (Norwegian University of Science and Technology, Trondheim, Norway), Adzhar Kamaludin, Awanis Romli, Anis Farihan Mat Raffei, Danakorn Nincarean A/L Eh Phon, Aziman Abdullah and Gan Leong Ming (Universiti Malaysia Pahang, Malaysia), Nurbiha A. Shukor (Universiti Teknologi Malaysia, Johor Bahru, Malaysia), Mohd Shukri Nordin (International Islamic University Malaysia, Selangor, Malaysia) and Suria Baba (Universiti Malaysia Kelatan, Kota Bharu, Malaysia). They note that there has been rapid growth in Blended Learning (BL) adoption, but few researches focused on adoption issues related to learners, academic staffs and management. Their study develops a model to facilitate university policy makers in their decisionmaking to assess students learning and academic staffs teaching outcome and also explores the factors that influence BL adoption in universities. Findings reveal that supportive factors, attitude, learning mode, satisfaction, course management, and ease of use positively predict the perception of learners and academic staffs' to adopt BL.

Learning analytics is an emerging field in which educators and researchers use data to improve student educational experiences. Data science syllabi measuring its content by Alon Friedman (USF, Tampa, Florida, USA) notes that one of the most common courses offered by higher academic institutions in the US is data science. This paper examines the data science syllabi found in today's academic sector and compares the results to those of Friedman's, Technology, Pedagogy and Education study of Big Data syllabi. The study found that the most frequently used communication engagement tool, according to the syllabi, was discussion forums with instant message applications being second.

The next paper discusses the role of instructional designers in supporting the Open Educational Resources (OER) movement in higher education, and comes from Xinyue Ren (Ohio University, Athens, USA). The undefined figure: Instructional designers in the open educational resource (OER) movement in higher education points out that due to the increasing cost of higher education, previous studies indicated the feasibility of adopting OER to lower students' educational expenses and to equalize their learning opportunities, but many instructors face barriers including lack of time, motivation and knowledge of quality evaluation to adoption of OER.

A neural network solution for forecasting labor demand of drop-in peer tutoring centers with long planning horizons by Rick Brattin, Randall S. Sexton, Wenqiang Yin and Brittaney Wheatley (Missouri State University, Springfield, USA), follows. The paper notes that like many other service organizations, drop-in peer tutoring centres often struggle to determine the required number of qualified tutors necessary to meet learner expectations. This study builds upon the flexible demand literature by exploring the use of neural networks for labour demand forecasting for a drop-in peer tutoring centre of a large university.

What follows is: Investigating the impact of university students' smartphone addiction on their satisfaction with classroom connectedness from Kamal Ahmed Soomro (Institute of Business Management, Karachi, Pakistan), Sajid Ali Yousuf Zai (National University of Modern Languages, Islamabad, Pakistan), Nasrullah (University of Wah, Wah Cantt., Pakistan) and Quratul Ain Hina (National University of Modern Languages, Islamabad, Pakistan). The findings of this study indicated that university students, from both genders, were highly addicted to the use of smartphones, 
but suggest significant differences in the levels of students' addiction to smartphones between undergraduate and graduate students.

Bimal Aklesh Kumar, Munil Shiva Goundar and Sailesh Saras Chand (Fiji National University, Suva, Fiji) next offer: Usability guideline for Mobile learning applications: an update. The paper notes that mobile learning application developers have to overcome inherent limitations imposed by mobile devices in order to produce usable applications, but that there are usability guidelines available to assist in the design process but with technological improvements. Their paper proposes an updated usability guideline to assist in the design process of mobile learning applications.

Using the HOT-fit model to predict the determinants of E-learning readiness in higher education: a developing Country's perspective is from Marva Mirabolghasemi and Sahar Hosseinikhah Choshaly (Islamic Azad University, Lahijan, Iran) and Noorminshah A. Iahad (Universiti Teknologi Malaysia, Johor Bahru, Malaysia). They point out that E-learning readiness has been initiated in higher education institutions in an attempt to improve institutions' service delivery. The purpose of their described study was to investigate the impact of human, organizational, and technological factors on students' e-learning readiness. The results indicated that computer self-efficacy, management support, relative advantage, compatibility, and complexity are significant factors that influence students' e-learning readiness.

A machine learning algorithm framework for predicting students' performance: $A$ case study of baccalaureate students in Morocco describes how predicting academic results is one of the solutions that aims to monitor the progress of students and anticipates students at risk of failing the academic pathways. This paper describes research by Aimad Qazdar, Brahim Er-Raha, Chihab Cherkaoui and Driss Mammass (Zohr University, Agadir, Morocco). The paper presents a framework for predicting student performance based on Machine Learning algorithm at H.E.K high school in Morocco from 2016 to 2018. The model was analyzed and tested using student data collected from The School Management System "MASSAR" (SMS-MASSAR).

MOOCs are becoming more and more involved in the pedagogical experimentation of universities whose infrastructure does not respond to the growing mass of learners say Mourdi Youssef, Sadgal Mohammed, El Kabtane Hamada and Berrada Fathi Wafaa (CADI AYYAD University, Marrakech, Morocco) in their paper titled: A predictive approach based on efficient feature selection and learning algorithms' competition: Case of learners' dropout in MOOCs. They argue that this pedagogical model faces a large dropout rate of enrolled learners, an automatic determination of relevant attributes for analysis, classification, interpretation and prediction from MOOC learners' data will allow instructors to streamline interventions for each class.

Cybersecurity education and training are being conducted on an ever-increasing scale, as most organisations need to improve their readiness in dealing with the more and more frequent cyberattacks say Razvan Beuran (Japan Advanced Institute of Science and Technology, Ishikawa, Japan), Dat Tang Japan Advanced Institute of Science and Technology, Ishikawa, Japan and Delivion GmbH, Am Forderturm, Mûlheim an der Ruhr, Germany), Zheyu Tan, Shinobu Hasegawa, Yasuo Tan and Yoichi Shinoda (Japan Advanced Institute of Science and Technology, Ishikawa, Japan) in their paper: Supporting cybersecurity education and training via LMS integration: CyLMS. Most systems used for education and training purposes are built from scratch, highly customised, and often proprietary. In this paper, they present an approach of 
integrating cybersecurity training activities, both for technical and awareness training, with a Learning Management Systems (LMSs) - CyLMS to provide integration from a content point of view with most LMSs through the use of the SCORM format for packaging the training content.

Investigating multimedia effects on concept map building: Impact on map quality, information processing and learning outcome describes how two experimental studies were carried by the authors: M. Sanchiz, J. Lemarié and A. Chevalier (University of Poitiers, France), J. Cegarra (University of Albi, France), P. V. Paubel (University of Poitiers, France), L. Salmerón (Univeristy of Valencia, Spain) and F. Amadieu (University of Poitiers, France), to investigate whether adding multimedia features in a concept mapping task would improve the quality of the map built by students and promote more effective learning with expository hypertexts. Results showed that multimedia presentation did lead learners to spend more time building the concept map and to build more coherent maps.

Mind the gap: Cognitive active learning in virtual learning environment perception of instructors and students was contributed by Fenio Annansingh (City University of New York, USA) who states that use of a virtual learning environment is increasingly gaining popularity with university students and instructors. They are said to increase flexibility and promote independent learning. This paper seeks to explore the disparity between students' and the instructor's perceptions of cognitive active learning experience in a virtual learning environment. The results showed that instructors believe students are often not intrinsically motivated and consequently do not automatically experience deep learning in the virtual learning environment without the appropriate instructional support.

The next paper: Participants and completers in programming MOOCs by Piret Luik, Lidia Feklistova, Marina Lepp, Eno Tõnisson, Reelika Suviste, Maria Gaiduk, Merilin Säde and Tauno Palts (University of Tartu, Estonia) points out that there are millions of MOOC participants who vary in gender, age, educational level, employment status and intentions. They point out that although MOOC participants' characteristics have been studied, there is still a lack of knowledge of the divergence between the participants and completers of MOOCs with different levels of difficulty, and their study aimed to determine the demographic and social background characteristics of participants and completers in three programming MOOCs with different difficulty levels. It was found that the difficulty of a topic is related to gender, age and educational level distribution in MOOCs.

Library and information science experts around the globe are currently exploring ways of capitalizing student workflow data within library walls and Stavroula SantGeronikolou (University Carlos III of Madrid, Spain) and Dimitris Kouis and Alexandros Koulouris (University of West Attica, Athens, Greece) discuss this in: Capitalizing on new forms of academic library's intellectual assets: a new library mobile application proposition. They designed and pilot-tested a user-driven lightweight application that envisions library as a crucial contributor of co-curricular data to learner profiles' contextual integrity. The participants felt positive about the need to develop a culture that fosters the reconsideration of library value constituents and their new dynamic role in the educational context, and the pilot-tested application could serve as a reference for the improvement of academic library use data collection practices. 
A review of tools and techniques for computer aided pronunciation training (CAPT) in English describes work by Chesta Agarwal and Pinaki Chakraborty (Netaji Subhas University of Technology, New Delhi, India). They note that widespread use of English in the academia and business is leading an increasing number of people to learn English as a second or a foreign language. Computer aided pronunciation training (CAPT) systems are used by non-native English speakers for improving their English pronunciation. They classified the CAPT systems for English into four categories on the basis of the technology used in them and studied the salient features of each category. They recommend collaboration between language teachers and software developers to develop CAPT tools, and their wide dissemination and integration within the curriculum at school and university levels.

Emad A. S. Abu-Ayyash and Christopher Hill (The British University in Dubai, United Arab Emirates) next offer: The impact of integrating technology into students' presentations on peer evaluation in higher education. In the study, students peer reviewed presentations, and two external raters evaluated the presentations based on a rubric adapted from Savory. The findings showed that student scores on the attitudinal scale and their holistic rankings correlated positively with the degree of technology employed in the presentations. External raters' evaluations, however, did not generally accord with the student-raters'.

Fine-grained affect detection in learners' generated content using machine learning was contributed by: Emmanuel Awuni Kolog (University of Ghana Business School, Legon Accra, Ghana), Samuel Nii Odoi Devine (Presbyterian University College, Okwahu, Ghana), Kwame Ansong-Gyimah (University of EducationWinneba, Kumasi, Ghana) and Richard Osei Agjei (University of Central Nicaragua, Managua, Nicaragua). In their paper they argue that learners' adaptation to academic trajectory is shaped by several influencing factors that ought to be considered while attempting to design an intervention towards improving academic performance, and that emotion is one such factor. This paper provides an overview of a machine learning application for detecting emotions in text through a Support vector machine learning system. Real time data from using the system in counselling delivery and collected students' life stories were used for evaluating the performance of the classifiers.

The next paper comes from Northern Ireland and Ireland and was contributed by: Stephen Roulston (Ulster University, Coleraine, Northern Ireland, UK), Pamela Cowan (Queen's University, Belfast, Northern Ireland, UK), Martin Brown (Dublin City University, Dublin City, Ireland), Roger Austin (Ulster University, Coleraine, Northern Ireland, UK) and Joe O'Hara (Dublin City University, Dublin City, Ireland). All aboard or still at check-in? Teacher educators' use of digital technologies: Lessons from a small island points out that although teachers are increasingly integrating ICT into formal education, an important expectation is that Initial Teacher Educators model their own practice as well as developing digital skills and competencies in pre-service teachers. Findings suggest that, while there are certainly pockets of excellence and some individual models of good practice, it is evident that there is a limited coherent integration of ICT within and across Initial Teacher Education providers, despite efforts to achieve this.

The next paper: Wirelessly bridging the homework gap: Technical options and social challenges in getting broadband to disconnected students, describes research by: Bianca C. Reisdorf (University of North Carolina at Charlotte, USA), Aleksandr 
Yankelevich (Federal Communications Commission, Washington DC, USA), Mitch Shapiro (Michigan State University, East Lansing, USA) and William H. Dutton (University of Oxford, UK). They point out that three million households with school-aged children in the United States do not have any Internet service at home, and $18 \%$ do not have a broadband connection, creating a 'homework gap' between those who can access the Internet to support their schoolwork at home, and those who cannot. Based on a series of empirical case studies of efforts to develop wireless projects across the United States, coupled with a review of relevant spectrum and wireless regulations, this study informs academics and practitioners how different wireless broadband technologies can help bridge the gap.

In Investigation of pre-service computer science Teachers' CS-unplugged design practices, Polat Sendurur (Ondokuz Mayis University, Samsun, Turkey) describes how Computer Science Unplugged (CS-Unplugged) has been evolving in computer science education. The author notes that this is a promising approach especially for introductory programming skills and computer science concepts. In this study, CS-Unplugged activity creation skills of pre-service computer teachers were examined. It was found that participants lacked competence in designing CS-Unplugged activities.

The use of a serious game in entrepreneurship teaching is from Yousra Charrouf (Boulevard Mohammed Ben Abdellah Regragui-Madinat Al Irfane-B.P, Rabat, Morocco) and Mourad Taha Janan (Boulevard Mohammed Ben Abdellah RegraguiMadinat Al Irfane-B.P, Morocco and Ecole Normale Supérieure de l'Enseignement Technique, Mohammed V University in Rabat, Rabat, Morocco). This research examines the use of a Serious Game at the end of an entrepreneurship course, following experiential learning theory which states that learning cannot take place if students are unable to experiment what they are learning in class. This is especially true in an entrepreneurship course where understanding of how a company works cannot be complete without attempting to simulate what is like to be an entrepreneur in real life. The Serious Game makes this possible, and the paper discusses the possibility of adopting Serious Games as a learning tool.

The last paper in this issue is: Open educational resources (OER) Edupreneurship business models for different stakeholders by Hamda Darwish (Shinas, Oman). The paper examines the emergence of Open Educational Resources (OER) in higher education institutions within educational entrepreneurship, hereafter edupreneurship, and offers a business models for different stakeholders. The paper concludes that OER environments process unstable amalgamations of networks that continually changes to adapt to the complexity, multi-functioning and multi-processing of customers and providers' motivations. OER projects disrupt the educational market worldwide, not due to the OER humanistic view of Openness as 'free of charge' and 'for free use' but to Openness being a premium business value that creates edupreneurship opportunities within the digital age.

\section{Arthur Tatnall}

Editor-in-Chief

Publisher's note Springer Nature remains neutral with regard to jurisdictional claims in published maps and institutional affiliations. 